\title{
Nutritional Requirements for Growth of Dispira cornuta in Axenic Culture
}

\author{
By N. SINGH* \\ Department of Biological Sciences, University of Exeter, Exeter EX 44 PS
}

(Received 2 September 1974; revised 20 January 1975)

\section{INTRODUCTION}

The nutritional requirements of haustorial mycoparasites remain uncertain, even though extensive axenic growth of certain mycoparasites has been obtained following the addition of a growth factor, mycotrophein, to an appropriate basal medium (Barnett \& Lilly, I958; Whaley \& Barnett, I963; Gain \& Barnett, 1970; Calderone \& Barnett, I972). Limited growth of mycoparasites in the absence of host extracts has been reported for Syncephalis (Ellis, I966) and Dispira parvispora (Brunk \& Barnett, I966). Barnett (I970) successfully cultured four haustorial mycoparasites including Dispira cornuta on a glycerol-casein hydrolysate medium, and Binder \& Barnett (1974) reported excellent axenic growth of Tieghemiomyces parasiticus on a glycerol-casein hydrolysate or amino acid medium.

There are different reports regarding the nutrition of D. cornuta. Ayers (1933) reported abundant axenic growth on natural media such as meat, fish and eggs. However, Kurtzman (I968) was unable to confirm Ayers' results. Out of five isolates of $D$. cornuta studied by Kurtzman only three made fair axenic growth on glycerol or acetate media in the presence of host extract, and these three isolates failed to utilize glucose. Using Kurtzman's isolate I, Barker \& Barnett ( 1973 ) reported that, in a medium containing glycerol, increasing amounts of casein hydrolysate, L-glutamic acid and L-aspartic acid supported correspondingly increasing amounts of growth, with an optimum at $40 \mathrm{~g} / \mathrm{l}$. L-Aspartic acid was the best nitrogen source. How such large amounts of L-aspartic acid and L-glutamic acid were kept in solution when the solubilities of these amino acids at $25^{\circ} \mathrm{C}$ are 5 and $8.64 \mathrm{~g} / \mathrm{l}$ respectively was not explained. It is therefore doubtful whether either of these amino acids was completely dissolved at the optimum concentration for the growth of the fungus $(40 \mathrm{~g} / \mathrm{l})$.

To understand the physiology of this very specialized group of mycoparasites, the nutritional requirements of a large number of species and isolates need to be investigated. I report the results of a nutritional study of an isolate of $D$. cornuta.

\section{METHODS}

Organism. A culture of Dispira cornuta growing on Cokeromyces recurvatus originating from the Commonwealth Mycological Institute, Kew, Surrey (C.M.I. No. 7759I) was obtained from the Botany Department, Birkbeck College, University of London.

Cultures of the mycoparasite free of its host were established by lifting the sporangiophores of the parasite under a binocular microscope with a fine sterile needle and streaking these on solidified basal medium (see below). Care was taken to exclude the host sporangiophores. After the spores of the mycoparasite had germinated, hyphal tips were transferred

* Present address: Department of Botany, Fourah Bay College, University of Sierra Leone, Freetown, Sierra Leone. 
to fresh basal medium and the pure culture thus established was maintained on this medium.

Media and standard conditions. The basal medium (BM) consisted of: glucose, $20 \mathrm{~g}$; L-asparagine, $2 \mathrm{~g}$; $\mathrm{K}_{2} \mathrm{HPO}_{4}$, I g; $\mathrm{MgSO}_{4} \cdot 7 \mathrm{H}_{2} \mathrm{O}$, $0.5 \mathrm{~g}$; thiamine, $500 \mu \mathrm{g}$; distilled deionized water to I 1 ; buffered at $\mathrm{pH} 6.0$ by $0.0 \mathrm{I} \mathrm{M}$-phosphate buffer. Concentrations of different carbon and nitrogen sources, where these were substituted for glucose or asparagine in $\mathrm{BM}$, are specified below. Liquid medium $(25 \mathrm{ml})$ was dispensed in $100 \mathrm{ml}$ rimless conical flasks with Oxoid metal caps. Since shaking enhanced growth considerably, cultures were shaken on a reciprocal shaker at $24 \pm \mathrm{I}{ }^{\circ} \mathrm{C}$. Four replicates constituted a sample. For dry weight determinations, mycelium was filtered and washed through sintered glass crucibles and dried at $80{ }^{\circ} \mathrm{C}$ overnight.

Inoculum. Mycelium of the mycoparasite grown on liquid BM was blended for I min in a Waring blender and washed three times with sterile distilled water by centrifugation. The final pellet was resuspended in $20 \mathrm{vol}$. of sterile distilled water and $\mathrm{I} \mathrm{ml}$ of this suspension was used to inoculate each flask.

Analysis. Glucose was determined by the method of Loewus (1952). Total nitrogen was converted to ammonia by a modification of the technique of Lang (I958), selenium oxychloride being replaced by an equivalent amount of selenium dioxide. In the conversion of amide of asparagine to ammonia and the distillation of ammonia, the method of Conway (I950) was followed. Ammonia determinations were done by the Nesslerization procedure of Yuen \& Pollard (1952).

\section{RESULTS}

\section{Effect of different carbon sources}

Carbon sources were employed at concentrations which gave carbon equivalent to $2 \%$ $(w / v)$ glucose in the medium. The best growth occurred on starch. Glycerol, acetate and several sugars were poorly utilized (Table I).

\section{Effect of different nitrogen sources}

Various nitrogen sources provided nitrogen equivalent to $0.25 \%$ asparagine. There was good utilization of casein hydrolysate, urea, asparagine, aspartic acid, serine and arginine (Table 1). Glutamic acid, glycine and ammonium sulphate were intermediate sources of nitrogen, while alanine, cystein, glutamine, leucine, phenylalanine and peptone were poorly utilized. Only slight growth occurred on histidine, lysine, methionine, proline, threonine, valine and potassium nitrate.

An increase in the rate of growth and total dry weight of mycelium, caused by increased concentrations of casein hydrolysate and two amino acids in the medium, has been reported by Barker \& Barnett (1973) for another isolate of $D$. cornuta, although their results are doubtful (see introduction). We therefore investigated the effects of increased concentrations of asparagine and casein hydrolysate in the medium, with $2 \%(\mathrm{w} / \mathrm{v})$ glucose as carbon source. Increase in asparagine from 0.25 to $2 \%(\mathrm{w} / \mathrm{v})$ did not produce significantly higher yields of mycelium. However, final dry weight rose when the concentration of casein hydrolysate was increased above $0.37 \%$ and was optimal at $\mathrm{I} .48 \%$ (equivalent to I \%, w/v, asparagine in $\mathrm{N}$ content). At $2.96 \%(\mathrm{w} / \mathrm{v})$ casein hydrolysate (equivalent to $2 \%$ asparagine in $\mathrm{N}$ content), there was a decline in growth which became very marked at $5.92 \%$ casein hydrolysate (equivalent to $4 \% \mathrm{w} / \mathrm{v}$, asparagine in $\mathrm{N}$ content).

To determine whether asparagine and casein hydrolysate act as carbon as well as nitrogen sources, the spent media from the above experiment were analysed for residual asparagine 
Table I. Yield of D. cornuta on media with various carbon sources, nitrogen sources, and amendments

\begin{tabular}{|c|c|c|c|c|c|}
\hline & $\begin{array}{c}\text { Yield* } \\
\text { (mg dry wt/ } \\
\text { flask) }\end{array}$ & $\begin{array}{l}\text { Final } \\
\text { pH }\end{array}$ & & $\begin{array}{c}\text { Yield* } \\
\text { (mg dry wt/ } \\
\text { flask) }\end{array}$ & $\begin{array}{c}\text { Final } \\
\mathrm{pH}\end{array}$ \\
\hline Carbon source & \multicolumn{5}{|c|}{ Nitrogen source (cont.) } \\
\hline Glucose & $78 \cdot 0 \pm 3 \cdot 8$ & $4 \cdot 7$ & L-Leucine & $25 \cdot 0 \pm 2 \cdot 3$ & 4.0 \\
\hline Fructose & $68 \cdot 3 \pm 6 \cdot 7$ & 5.9 & L-Lysine & $3.5 \pm 0.7$ & $4 \cdot 2$ \\
\hline Rhamnose & $6 \cdot 0 \pm 2 \cdot 0$ & $7 \cdot 0$ & L-Methionine & $8 \cdot 0 \pm 0 \cdot 7$ & $4 \cdot 2$ \\
\hline Galactose & $8 \cdot 8 \pm 0.7$ & $7 \cdot 2$ & L-Proline & $3 \cdot 5 \pm \mathrm{I} \cdot 8$ & $4 \cdot 2$ \\
\hline Arabinose & $2 \cdot 3 \pm 0 \cdot 7$ & $6 \cdot 5$ & L-Phenylalanine & $28 \cdot 0 \pm 2 \cdot 7$ & $4 \cdot 1$ \\
\hline Xylose & $5 \cdot 3 \pm 3 \cdot 5$ & $6 \cdot 4$ & DL-Serine & $6 \mathrm{I} \cdot 0 \pm 2 \cdot 9$ & 3.9 \\
\hline Lactose & $4 \cdot 8 \pm 2 \cdot 5$ & $6 \cdot 5$ & Peptone & $30 \cdot 8 \pm 0 \cdot 7$ & $4 \cdot 4$ \\
\hline Maltose & $65 \cdot 5 \pm 3 \cdot 2$ & $5 \cdot \mathrm{I}$ & L-Threonine & $15 \cdot 5 \pm 1 \cdot 8$ & 4.0 \\
\hline Sucrose & $4 \cdot 0 \pm \mathrm{I} \cdot 0$ & $6 \cdot I$ & L-Valine & $15 \cdot 3 \pm 1 \cdot 8$ & $3 \cdot 9$ \\
\hline Starch & $96 \cdot 3 \pm 6 \cdot 8$ & 4.9 & Casein hydrolysate & $87.5 \pm 3.5$ & $4 \cdot 3$ \\
\hline Dextrin & $87.8 \pm 8 \cdot 2$ & $6 \cdot 2$ & Potassium nitrate & $14.3 \pm 1.8$ & $4 \cdot 2$ \\
\hline Glycerol & $6 \cdot 5 \pm 2 \cdot 4$ & $7 \cdot \mathrm{I}$ & Ammonium sulphate & $48 \cdot 8 \pm 5 \cdot 4$ & $4 \cdot I$ \\
\hline Potassium acetate & $4 \cdot 0 \pm 2 \cdot 0$ & $8 \cdot 2$ & Urea & $90 \cdot 3 \pm 5 \cdot 7$ & 4.5 \\
\hline Nitrogen source & \multicolumn{5}{|c|}{ Amendment $\uparrow$} \\
\hline L-Asparagine & $78 \cdot 5 \pm 4 \cdot I$ & $4 \cdot 0$ & None (BM without thi) & $26 \cdot 3 \pm 2 \cdot 3$ & $4 \cdot 2$ \\
\hline L-Aspartic acid & $75 \cdot 5 \pm 3 \cdot 4$ & $4 \cdot 2$ & $\mathrm{BM}+$ thi & $71 \cdot 8 \pm 2 \cdot 2$ & $4 \cdot 4$ \\
\hline L-Arginine & $63.0 \pm 5.3$ & $3 \cdot 8$ & $\mathrm{BM}+\mathrm{o} . \mathrm{v}$. & $39 \cdot 5 \pm 3 \cdot 4$ & $4 \cdot 2$ \\
\hline L- $\alpha$-Alanine & $38 \cdot 3 \pm 2 \cdot 9$ & 3.9 & $\mathrm{BM}+$ thi + o.v. & $82 \cdot 5 \pm 7 \cdot 5$ & $4 \cdot 6$ \\
\hline L-Cystein & $36 \cdot 8 \pm 4 \cdot 6$ & 3.9 & $\mathrm{BM}+$ m.e. & $31 \cdot 5 \pm 5 \cdot 0$ & $4 \cdot 5$ \\
\hline L-Glutamic acid & $42 \cdot 5 \pm 3 \cdot 1$ & $4 \cdot 5$ & $\mathrm{BM}+$ m.e. + thi & $105 \cdot 8 \pm 4 \cdot 3$ & $4 \cdot 6$ \\
\hline Glutamine & $27 \cdot 3 \pm 2 \cdot 9$ & $3 \cdot 9$ & $\mathrm{BM}+$ m.e. + o.v. & $44 \cdot 8 \pm 4 \cdot 4$ & $4 \cdot 3$ \\
\hline Glycine & $42 \cdot 8 \pm 3 \cdot 5$ & $4 \cdot 2$ & $\mathrm{BM}+$ m.e. + thi + o.v. & $99 \cdot 0 \pm 4 \cdot 9$ & $4 \cdot 3$ \\
\hline L-Histidine & $4 \cdot 0 \pm 0 \cdot 7$ & $3 \cdot 8$ & & & \\
\hline
\end{tabular}

* Mean of four replicates, with standard errors.

$+\mathrm{BM}$, basal medium. thi, Thiamine. o.v., Other vitamins, consisting of $(\mu \mathrm{g} / \mathrm{l})$ : thi, 500; biotin, I0; calcium pantothenate, 400; $p$-amino benzoic acid, I00; folic acid, 100 ; mesoinositol, 2000; pyridoxine, 400; riboflavin, 200; nicotinamide, 100 . m.e., Microelements - to $\mathrm{I} 1$ of $\mathrm{BM}$ were added $10 \mathrm{ml}$ of a stock solution containing (mg/l distilled deionized water): $\mathrm{CuSO}_{4} \cdot 5 \mathrm{H}_{2} \mathrm{O}, 5 ; \mathrm{FeSO}_{4} \cdot 7 \mathrm{H}_{2} \mathrm{O}, \mathrm{I}$; $\mathrm{MnCl}_{2}, \mathrm{I} ; \mathrm{ZnSO}_{4} \cdot 7 \mathrm{H}_{2} \mathrm{O}, 7 \cdot 5$.

and casein hydrolysate, production of ammonia and residual glucose. Unused nitrogenous compounds were still present in the media after 6 days of growth except at the lowest concentration. A considerable portion of the nitrogenous compounds decomposed remained in the medium as ammonia, and media with higher concentrations of asparagine and casein hydrolysate showed correspondingly higher concentrations of ammonia. In another experiment, analysis of spent medium showed that the fungus did not utilize asparagine carbon even when the glucose concentration in the medium was reduced to $0.05 \%$.

\section{Effect of vitamins and microelements}

To study the effects of vitamins and trace elements, BM was used with various amendments. Thiamine stimulated growth, while other vitamins had little or no effect. Microelements promoted growth in the presence of thiamine but not in the presence of other vitamins (Table I).

Shigo, Anderson \& Barnett (196I) reported that an increase in the concentration of manganese in the medium was associated with an increase in the degree of parasitism of Piptocephalis xenophila. In the present study, however, additions to the basal medium of microelements and manganese alone at concentrations four times higher than those used in the previous experiment did not enhance growth significantly. 
DISCUSSION

The utilization of glycerol and failure to utilize glucose and other sugars, first discovered by Kurtzman (I968), was emphasized as the key to the successful axenic culturing of $D$. cornuta and other haustorial mycoparasites by Barnett (1970). However, in the present study glycerol and acetate were not utilized, whereas glucose and other sugars were. Starch was the best carbon source but it is possible that it was partially hydrolysed during autoclaving and it was the products thus released which were responsible for the good growth. The good growth on glucose, fructose and maltose cannot be related to the reducing nature of these sugars, since galactose, another reducing sugar, was not utilized well. This isolate used a wider range of nitrogen sources than that reported by Barker \& Barnett (1973) for their isolate. Ammonium sulphate, reported by Barker \& Barnett (I973) to be a poor source of nitrogen, was a reasonably good one. The poor utilization of nitrate is in agreement with the results obtained by Kurtzman (I968). The utilization of amino acids was not found to be related to their structure. For example, alanine was a good source of nitrogen, while histidine and lysine, belonging to the same group (basic), were not utilized. Optimal growth was obtained in media containing $\mathrm{I} \%$ asparagine or $\mathrm{I} \cdot 48 \%(\mathrm{w} / \mathrm{v})$ casein hydrolysate. There was a decline in growth at higher concentrations, probably because of toxicity caused by ammonia which builds up in cultures as the concentrations of nitrogen sources are increased. This could also explain the rise in final $\mathrm{pH}$ of cultures with increasing initial concentrations of nitrogen. These results are in contrast to those obtained by Barker \& Barnett (1973), who reported optimum growth of their isolate of $D$. cornuta with $40 \mathrm{~g}$ casein hydrolysate, L-aspartic acid or L-glutamic acid/1. The fungus had a deficiency for thiamine, but not for any other vitamin. Barker \& Barnett (1973) reported that their isolate had a clear deficiency for both thiamine and biotin. Some growth on basal medium without vitamins was probably due to the contamination of other constituents of the medium with vitamins. Microelements were stimulatory only in the presence of thiamine, and this stimulation was not due to manganese alone (Shigo et al. 1961).

This isolate of $D$. cornuta did not show the same nutritional pattern as other isolates of $D$. cornuta and other haustorial mycoparasites so far studied in axenic culture.

\section{REFERENCES}

AYERS, T. T. (1933). Growth of Dispira cornuta in artificial culture. Mycologia 25, 333-34I .

BARKER, S. M. \& BARNETT, H. L. (1973). Nitrogen and vitamin requirements for axenic growth of haustorial mycoparasite, Dispira cornuta. Mycologia $65,2 \mathrm{I}-27$.

BARNETT, H. L. (1970). Nutritional requirements for axenic growth of some haustorial mycoparasites. Mycologia 62, 750-760.

BarnetT, H. L. \& Lilly, V. G. (I958). Parasitism of Calcarisporium parasiticum on species of Physalospora and related fungi. West Virginia University Agricultural Experiment Station Bulletin $420 T$.

Binder, F. L. \& BarnetT, H. L. (I974). Amino acid requirements for the axenic growth of Tieghemiomyces parasiticus. Mycologia 66, 265-27I.

Brunk, M. \& Barnett, H. L. (1966). Mycoparasitism of Dispira simplex and D. parvispora. Mycologia 58, $518-523$.

Calderone, R. A. \& Barnett, H. L. (1972). Axenic growth and nutrition of Gonatobotryum fuscum. Mycologia 64, I53-I60.

Conway, E. J. (1950). Microdiffusion Analysis and Volumetric Error. London: Crosby and Lockwood.

Ellis, J. J. (1966). On growing Syncephalis in pure culture. Mycologia 58, 465-469.

Gain, R. E. \& BarnetT, H. L. (1970). Parasitism and axenic growth of the mycoparasite Gonatorhodiella highlei. Mycologia 62, I I22-1 I 29.

Kurtzman, C. P. (1968). Parasitism and axenic growth of Dispira cornuta. Mycologia 6o, 91 5-923. 
LANG, C. A. (1958). Simple microdetermination of Kjeldahl nitrogen in biological materials. Analytical Chemistry 30, 1692-1694.

Loewus, F. A. (1952). Improvement in anthrone method for determination of carbohydrates. Analytical Chemistry 24, 219.

Shigo, A. L., Anderson, C. D. \& Barnett, H. L. (I96I). Effects of concentration of host nutrients on parasitism of Piptocephalis xenophila and P. virginiana. Phytopathology 51, 616-620.

Whaley, J. W. \& Barnett, H. L. (I963). Parasitism and nutrition of Gonatobotrys simplex. Mycologia 55, I 99-2IO.

Yuen, S. H. \& Pollard, A. G. (1952). The determination of nitrogen in agricultural materials by the Nessler reagent. Journal of the Science of Food and Agriculture 3, 44I-447. 